\title{
Bone integration capability of nanopolymorphic crystalline hydroxyapatite coated on titanium implants
}

This article was published in the following Dove Press journal:

International Journal of Nanomedicine

16 February 2012

Number of times this article has been viewed

\section{Masahiro Yamada* \\ Takeshi Ueno* \\ Naoki Tsukimura \\ Takayuki Ikeda \\ Kaori Nakagawa \\ Norio Hori \\ Takeo Suzuki \\ Takahiro Ogawa}

Laboratory of Bone and Implant Sciences, The Weintraub Center for Reconstructive Biotechnology, Division of Advanced Prosthodontics, Biomaterials and Hospital Dentistry, UCLA School of Dentistry, Los Angeles, CA, USA

*These authors contributed equally to this work
Correspondence: Takahiro Ogawa Laboratory of Bone and Implant Sciences, The Jane and Jerry Weintraub Center for Reconstructive Biotechnology, Division of Advanced Prosthodontics, Biomaterials and Hospital Dentistry, UCLA School of Dentistry,

10833 Le Conte Avenue (B3-08I CHS), Box 951668, Los Angeles,

CA 90095-1668, USA

Tel + I 3108250727

Fax + I 3108256345

Email togawa@dentistry.ucla.edu
Abstract: The mechanism by which hydroxyapatite (HA)-coated titanium promotes bone-implant integration is largely unknown. Furthermore, refining the fabrication of nanostructured HA to the level applicable to the mass production process for titanium implants is challenging. This study reports successful creation of nanopolymorphic crystalline HA on microroughened titanium surfaces using a combination of flame spray and low-temperature calcination and tests its biological capability to enhance bone-implant integration. Sandblasted microroughened titanium implants and sandblasted + HA-coated titanium implants were subjected to biomechanical and histomorphometric analyses in a rat model. The HA was $55 \%$ crystallized and consisted of nanoscale needle-like architectures developed in various diameters, lengths, and orientations, which resulted in a 70\% increase in surface area compared to noncoated microroughened surfaces. The HA was free from impurity contaminants, with a calcium/phosphorus ratio of 1.66 being equivalent to that of stoichiometric HA. As compared to microroughened implants, HA-coated implants increased the strength of bone-implant integration consistently at both early and late stages of healing. HA-coated implants showed an increased percentage of bone-implant contact and bone volume within $50 \mu \mathrm{m}$ proximity of the implant surface, as well as a remarkably reduced percentage of soft tissue intervention between bone and the implant surface. In contrast, bone volume outside the $50 \mu \mathrm{m}$ border was lower around HA-coated implants. Thus, this study demonstrated that the addition of pure nanopolymorphic crystalline HA to microroughened titanium not only accelerates but also enhances the level of bone-implant integration and identified the specific tissue morphogenesis parameters modulated by HA coating. In particular, the nanocrystalline HA was proven to be drastic in increasing osteoconductivity and inhibiting soft tissue infiltration, but the effect was limited to the immediate microenvironment surrounding the implant.

Keywords: osseointegration, dental and orthopedic implant, nanotechnology, bone-implant integration, HA, calcium phosphate

\section{Introduction}

Nanosurface modification has been implemented to improve the efficacy of endosseous titanium implants at commercial and experimental levels. ${ }^{1-3}$ Although limited, in vitro studies provide information on their biological capability. Titanium surfaces with enhanced microscale and nanoscale morphological features exhibited improved osteoblastic behavior, such as increased cell attachment, proliferation, alkaline phosphatase activity, and upregulated gene expression of bone-related proteins, when compared to surfaces with microfeatures alone. ${ }^{4-7}$ Studies also revealed the new potential of nanofeatured titanium surfaces as a smart material for inducing cell-specific affinity, eg, selective attractiveness for osteogenic cells but not for fibroblasts. ${ }^{6,8-10}$ submit your manuscript | www.dovepress.com

Dovepress

http://dx.doi.org// 0.2147/IJN.S28082 
However, there is a critical lack of information describing the in vivo bone-implant integration capability of nanofeatured titanium materials. First, it should be strictly addressed whether nanofeatured surfaces solely affect the process or consequences of bone-implant integration, or both. Clinically, it is important to know whether the new surface increases the speed of bone formation or the level of bone-implant integration, or both. The answer would directly affect the decision-making process during treatment planning, such as the determination of required healing time and loading protocols of implants. More data are needed to identify the specific advantages of nanofeatured implant surfaces over the currently used microfeatured implant surfaces to justify their clinical use. ${ }^{1,3,5,6,8,11-15}$ Biologically, the following fundamental questions remain to be answered: do nanofeatured implant surfaces increase the strength of bone-implant integration? If so, is this strength attributable to the increased surface area of the implant, the increased interlocking between the implant surface and bone, or the promoted periimplant osteogenesis?

The authors believe that there are three major goals for nanostructuring technology in implant therapy: (1) to develop technologies with reasonable cost to enable mass production; (2) to create morphologically evident nanofeatures that can be defined; and (3) to demonstrate a biologically significant advantage over microfeatured implant surfaces, which are commonly used in current implant therapy. For instance, although creating bioinspired nanomorphology, where a biomaterial surface resembles biological molecules or tissue surfaces, may offer a new local environment for better cell-material interaction and tissue conductivity, the difficulty in applying these techniques to a large area practically limits its clinical application. ${ }^{6,15}$ Currently available nanotechnology-based commercial implants show less sophisticated and less definable morphology than aforementioned ideally created nanotopographies for experimental and exploratory purposes. ${ }^{6,16}$ It is difficult to characterize such surfaces, which raises concerns about how to link the surface features of these implants to their claimed biological effects. ${ }^{3,5,6,12}$ In modern implant therapy in both orthopedic and dental fields, titanium surfaces with microscale morphological features such as microroughness, microirregularity, microtopography, and other microscale architectures have an established significance and viability for clinical use. Therefore, it is a challenge for nanotechnologybased surface modifications to replace the currently available microfeatured surfaces.

Coating hydroxyapatite (HA) or other types of calcium phosphate on titanium surfaces has been extensively investigated to enhance the bone-implant integration capability. ${ }^{17-19}$ HA was initially used as an osteoconductivity enhancer for various materials because of its chemical interaction with osteogenic cells and the local environment by releasing ions necessary for bone formation. ${ }^{19,20}$ Despite the generally accepted biocompatibility of HA and calcium phosphate with bone, controversies still exist about their definite role in the bone-implant integration process and their application to dental and orthopedic implants. ${ }^{17,20,21}$ In particular, although the surface morphology of HA can be altered considerably by its coating process and degree of crystallization, the effect of the surface morphology of HA on its biological capability has rarely been addressed, which makes the interpretation of the effect of HA very difficult. For instance, it was reported that the effect of HA on osteoblasts varies depending on whether it is coated on smooth or grooved surfaces. ${ }^{22}$ Most of the previous studies that tested the biological capability of HA used high-temperature-sintered HA; such HA does not seem to manifest the definable microscale or nanoscale surface morphology, but has not been morphologically characterized fully. ${ }^{18,20,23-25}$

Apatite coating with microsurface morphology can be deposited on material surfaces by biomimetic mineralization process using simulated body fluid. ${ }^{26-30}$ In addition to the surface morphological features, the degree of crystallinity and chemical composition of the apatite can also be controlled. Other advantages of this method are that it does not require high-temperature processing, which allows nonmetal materials to be coated with apatite crystals. However, this process may not be appropriate for coating on three-dimensional materials or for mass production. In order to obtain a relatively thick $(>20 \mu \mathrm{m})$ HA coating on metals, thermal spray techniques such as the plasma spray process are generally used. ${ }^{17}$ The process requires fusing HA at very high temperatures of $10,000^{\circ} \mathrm{C}-20,000^{\circ} \mathrm{C}$. However, this high-temperature processing may contaminate molten copper from the spray nozzle, and more importantly, alter the calcium $(\mathrm{Ca}) /$ phosphorus $(\mathrm{P})$ ratio of the sprayed HA because of the decomposition and dissolution of phosphate components. These unfavorable chemical alterations then distort the $\mathrm{Ca} / \mathrm{P}$ ratio during recrystallization and result in unstable formation of HA crystallites. To coat titanium surfaces with a layer of $\mathrm{HA}$ with a proper $\mathrm{Ca} / \mathrm{P}$ ratio and defined nanomorphology, a flame spray technique that requires heating at $2700^{\circ} \mathrm{C}$ was employed, which is considerably lower than the temperature required for plasma spray. The sprayed HA was cooled and vacuum heated at $650^{\circ} \mathrm{C}$ to recrystallize $\mathrm{HA}$. 
Here, the successful coating of nanopolymorphic crystalline HA on microroughened titanium surfaces using a combination of flame spray and low-temperature calcination is reported. Next, it was determined if the nanopolymorphic crystalline HA-coated titanium can increase in vivo bone-implant integration in comparison to microroughened titanium surfaces. In order to establish the credibility of the result, nanopolymorphic crystalline HA was compared with microroughened titanium surfaces after verifying the advantage of the microroughened surface over a nonmicroroughened surface. To identify and isolate the contribution of nanopolymorphic crystalline HA to specific aspects of in vivo bone-implant integration, a comprehensive assessment of biomechanical, interfacial, and histomorphometric analyses was performed at multiple time points during healing in a rat model.

\section{Materials and methods}

\section{Nanocrystalline HA coating on titanium}

Titanium cylinders $(1 \mathrm{~mm}$ in diameter and $2 \mathrm{~mm}$ in length) were prepared by machining the Grade 5 titanium alloy (Ti-6Al-4V). To create microroughness, titanium samples were sandblasted with aluminum oxide $\left(\mathrm{Al}_{2} \mathrm{O}_{3}\right)$ micropowders. HA coating was performed by flame spraying HA on sandblasted surfaces. The flame was created using acetylene and oxygen gas, and air was used as a high-speed carrier gas for the spray. The spraying was carried out at $2700^{\circ} \mathrm{C}$ until the coat reached a thickness of $20 \mu \mathrm{m}$. The sprayed amorphous HA was vacuum heated at $650^{\circ} \mathrm{C}$ for 3 hours to calcinate. All samples were provided by Japan Medical Materials Corporation (Osaka, Japan).

The surface morphology of the machined surface, sandblasted surface, and sandblasted + HA-coated surface was examined by scanning electron microscopy (SEM) (XL30; Philips, Eindhoven, Netherlands) and atomic force microscopy (AFM) (SPM-9500J3; Shimadzu Corporation, Tokyo, Japan). Average roughness, peak-to-valley roughness, interirregularity space, and surface area were calculated. In addition, the titanium surfaces were examined for elemental composition and crystalline property using an energy dispersive X-ray (EDX) detector (JSM-5900LV; JEOL Ltd, Tokyo, Japan) and X-ray diffraction (XRD) (XD-3A; Shimadzu), respectively. The degree of crystallinity was determined by $\mathrm{HA} / \mathrm{Al}_{2} \mathrm{O}_{3} \mathrm{XRD}$ intensity ratio, where the $\mathrm{HA} / \mathrm{Al}_{2} \mathrm{O}_{3}$ ratio of the fully crystallized $\mathrm{HA}$ (HA sintered at $1000^{\circ} \mathrm{C}$ ) was used as $100 \%$ standard. Furthermore, the coated HA was dissolved in $7 \%$ hydrogen chloride and subjected to chemical analysis to calculate the molecular ratio of $\mathrm{Ca} / \mathrm{P}$ and to detect the potential contamination of minor impurities (iron, nickel, chromium, copper, zinc, arsenic, lead) using an inductively coupled plasma atomic emission spectrometer (S-2000; Shimadzu).

\section{Surgery}

Eight-week-old male Sprague-Dawley rats were anesthetized with $1 \%-2 \%$ isoflurane inhalation. Only left femurs were used to receive an implant. The left leg area was shaved and scrubbed with $10 \%$ providone-iodine solution and the distal half of the femur was carefully exposed via skin incision and muscle dissection. The flat surface close to the distal end was selected for implant placement. The implant site was prepared $10 \mathrm{~mm}$ from the distal edge of the femur by drilling with a $0.8 \mathrm{~mm}$ round burr and enlarged using reamers (\#ISO 090 and 100). For cooling and cleaning, the site was profusely irrigated with a sterile isotonic saline solution. One cylindrical implant that had been machined, sandblasted, or sandblasted + HA-coated was inserted into each prepared hole per femur. Muscle and skin were sutured separately with resorbable suture thread. The total number of animals used was 78 (54 animals for the push-in test in machined, sandblasted, and sandblasted + HA-coated implant groups at weeks two, four, and eight; 24 animals for histology for sandblasted and sandblasted + HA-coated implant groups at weeks two and four). This protocol was approved by the University of California at Los Angeles Chancellor's Animal Research Committee (Los Angeles, CA), and all experimentation was performed in accordance with the United States Department of Agriculture guidelines on animal research.

\section{Implant biomechanical push-in test}

The implant biomechanical push-in test was conducted to assess the biomechanical strength of bone-implant integration. The procedure details and method validation are described elsewhere. ${ }^{20,32}$ Femurs containing the cylindrical implant were harvested after 2, 4, and 8 weeks of healing and embedded into an autopolymerizing resin with the top surface at the implant level. A testing machine (Instron 5544 electromechanical testing system; Instron, Norwood, MA) equipped with a $2000 \mathrm{~N}$ load cell and a pushing rod (diameter $=0.8 \mathrm{~mm}$ ) was used to load the implant vertically downward at a crosshead speed of $1 \mathrm{~mm} /$ minute. The push-in value was determined by measuring the peak of the loaddisplacement curve. The push-in test was performed at weeks two, four, and eight of healing and six animals (six implants) were sacrificed for each of the implant surface groups at each time point $(n=6)$. 


\section{Morphological and elemental analyses of implant-tissue interface}

The morphological and elemental analyses of implant surfaces after the push-in test were used to examine the quality of bone-implant integration, in particular with respect to their adhesion properties at the interface, and the morphological and structural properties of bone. ${ }^{31,32}$ After the push-in test, the bone-implant complex from the selected implant specimens was carefully exposed and soaked in agitated water for 1 hour and dried under heat and vacuum. After carbon-sputter coating, the specimens were examined by SEM. The elemental composition of the tissues and the implant-tissue interface were analyzed by EDX.

\section{Histological preparation}

The implanted femur was harvested after 2 and 4 weeks of healing and fixed in $10 \%$ buffered formalin for 2 weeks at $4^{\circ} \mathrm{C}$. Specimens were dehydrated in an ascending series of alcohol rinses and embedded in a light-curing epoxy resin (Technovit 7200 VLC; Heraeus Kulzer, Wehrheim, Germany) without decalcification. Embedded specimens were sawed perpendicular to the longitudinal axis of the cylindrical implants at a site $0.5 \mathrm{~mm}$ from the apical end of the implant. Specimens were ground to a thickness of $30 \mu \mathrm{m}$ with a grinding system (Exakt Advanced Technologies GmbH, Norderstedt, Germany). Sections were stained with Goldner's trichrome stain and observed via light microscopy. The histology was performed for sandblasted and sandblasted + HA-coated implants at weeks two and four postimplantation, and six animals (six implants) were sacrificed for each of the implant surface groups at each time point $(n=6)$.

\section{Histomorphometry}

A $40 \times$ and $100 \times$ magnification lens and a $4 \times$ zoom on digital images were used for computer-based histomorphometric measurements (Image Pro-Plus; Media Cybernetics Inc, Bethesda, MD). To facilitate differentiation of tissue type, the images were color converted using image software (Figure 1). To identify the tissue structure details, microscopic magnification up to $200 \times$ was used. Implant histomorphometry has previously been established, which discriminates between implant-associated bone and nonimplant-associated bone..$^{33,34}$ Using this method, the tissues surrounding the implants were divided into two zones as follows: (1) near zone, the circumferential zone within $50 \mu \mathrm{m}$ of the cylindrical implant surface; and (2) far zone, the circumferential zone from $50 \mu \mathrm{m}$ to $200 \mu \mathrm{m}$ of the implant surface. The following variables were analyzed (Figure 1):

1. Bone-implant contact $(\%)=$ (sum of the length of boneimplant contact) $/$ (circumference of the implant) $\times 100$, where implant-bone contact was defined as the interface where bone tissue was located within $20 \mu \mathrm{m}$ of the implant surface without any intervening soft tissue.

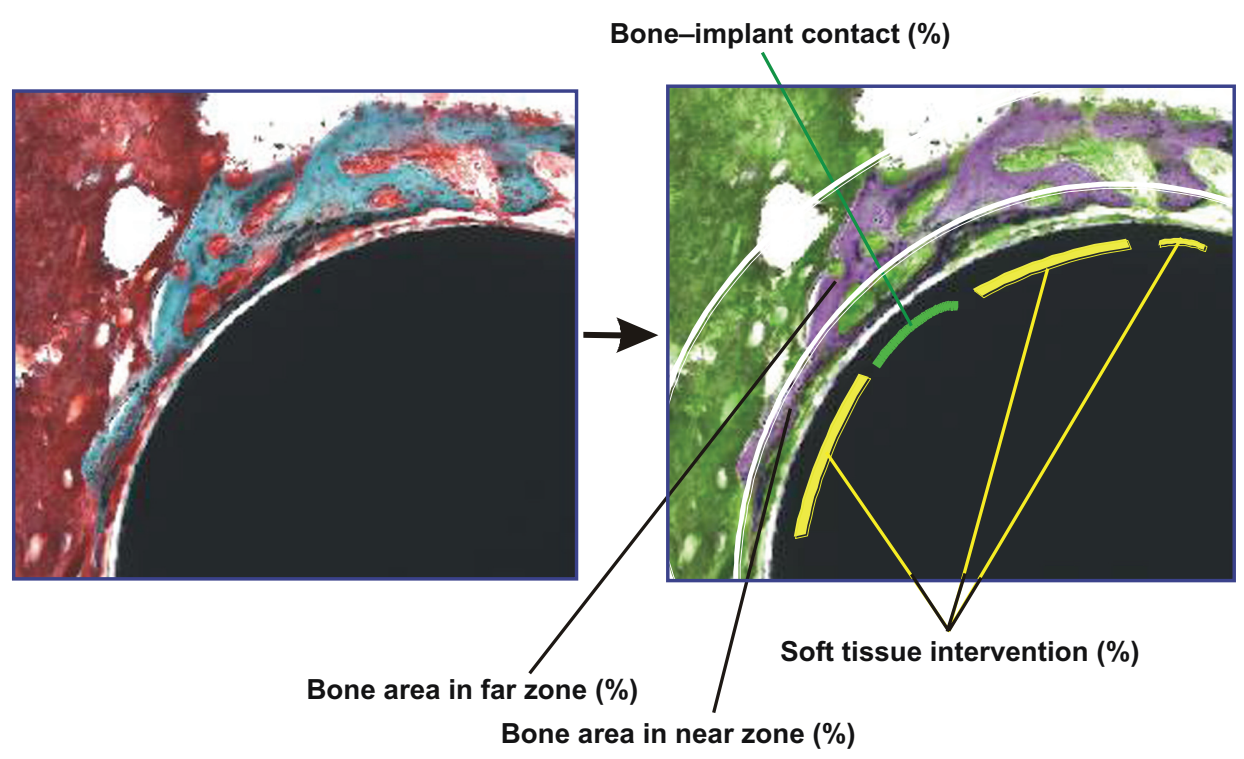

Figure I Description of histomorphometric analysis and parameters. Cross-sectional histological images were color converted to facilitate the discrimination of tissue types (from left to right images). To measure the bone area in the standardized vicinity levels from the implant surface, the tissue area was divided into two different zones: near ( $50 \mu \mathrm{m}$ proximity) and far $(50-200 \mu \mathrm{m})$ zones from the implant surface as segmented by white lines. The green lines represent the bone tissue in direct contact with the implant, while the yellow lines represent the bone tissue separated from the implant surface by soft tissue intervention. See the detailed description in the Materials and Methods section. 
2. Bone area in near zone $(\%)=($ bone area in near zone $) /$ (area of near zone) $\times 100$.

3. Bone area in far zone $(\%)=($ bone area in far zone $) /($ area of far zone) $\times 100$.

4. Soft tissue intervention $(\%)=$ (sum of the length of soft tissue intervening between bone and implant)/(sum of the length of bone surrounding an implant) $\times 100$.

\section{Statistical analyses}

Six samples were taken $(n=6)$ for surface roughness and chemistry evaluations, and biomechanical push-in test and histomorphometric analyses. Welch's method was used to compare the differences in these parameters between the different implant surfaces; $P<0.05$ was considered significant.

\section{Results \\ Creation of nanopolymorphic crystalline HA on microroughened titanium}

The three different surfaces prepared from the Ti-6Al-4V alloy exhibited diverse surface morphology (Figure 2). Low-magnification SEM images of machined surfaces showed parallel traces formed during the concentric machining process, while no definable micro- or submicronscale topography was observed in higher magnification images (Figure 2A). Sandblasted surfaces showed typical microscale roughness and irregular bumps and dents from the blasting procedure. Sandblasted + HA-coated surfaces also showed microscale roughness and irregularity in low-magnification images (right top image in Figure 2A)
A
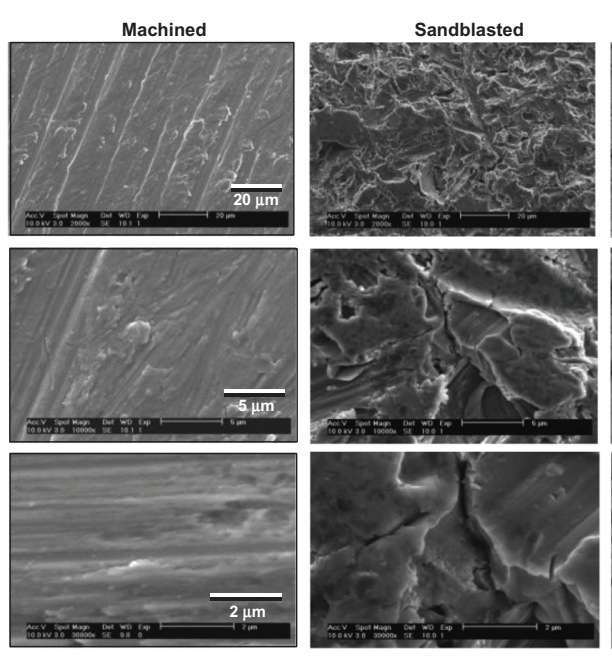

B
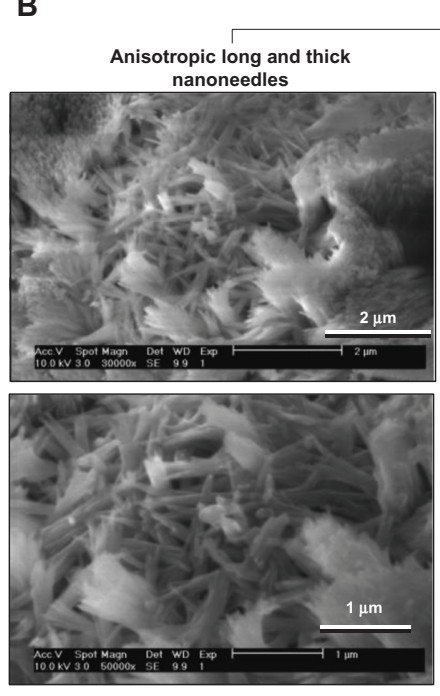

Nanopolymorphic features of HA

Isotropic short and thin nanoneedles
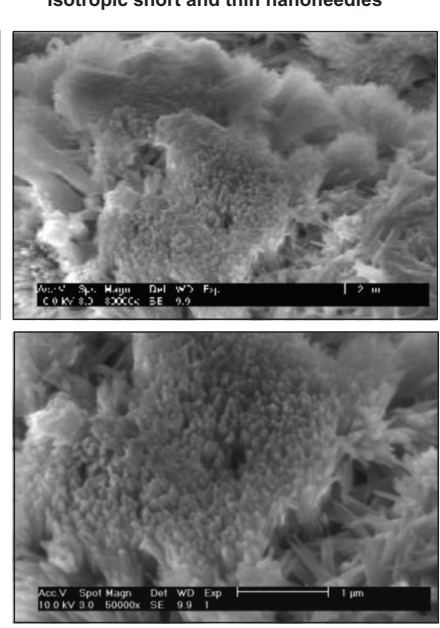

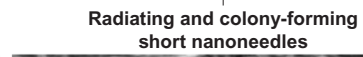

Sandblasted and HA-coated
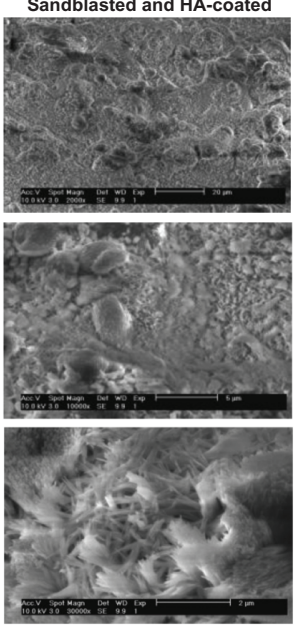
short nanoneedles
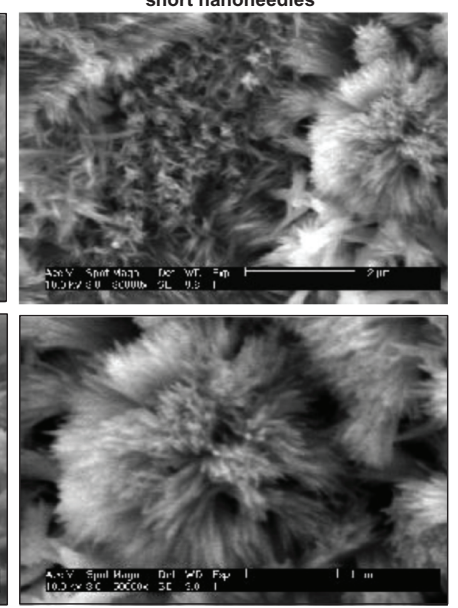

Figure 2 Creation of nanopolymorphic hydroxyapatite on microroughened titanium. Three different surfaces were prepared from Grade 5 titanium alloy (Ti-6Al-4V). (A) Low- and high-magnification scanning electron microscopic images of machined, sandblasted, and sandblasted + hydroxyapatite-coated surfaces. (B) Further close-up scanning electron microscopic images of the sandblasted + hydroxyapatite-coated surfaces showing nanopolymorphic features of nanoscale needle-like architectures in various diameters, lengths, and orientations.

Abbreviation: HA, hydroxyapatite. 
as a result of sandblasting. High-magnification images (bottom images in Figure 2A) showed a clear distinction between sandblasted surfaces and sandblasted + HA-coated surfaces: sandblasted + HA-coated surfaces exhibited finer surface structures at the submicron scale, while the sandblasted surfaces were nearly amorphous at this scale.

Further magnified SEM images revealed the formation of various nanoscale architectures on sandblasted + HA-coated surfaces (Figure 2B). The nanoarchitectures consisted of (1) anisotropically developed relatively long and thick nanoneedles (left images in Figure 2B); (2) densely and isotropically developed short and thin nanoneedles (middle images); (3) short and thin nanoneedles radiating and forming colonies (right images). The long and thick nanoneedles were 900-1600 $\mathrm{nm}$ in length and 80-200 $\mathrm{nm}$ in diameter (left panel in Figure 2B), while the short and thin nanoneedles were 300-900 $\mathrm{nm}$ in length and 20-70 $\mathrm{nm}$ in diameter (middle and right panels in Figure 2B). Because of these three distinct nanomorphological features, the surface was defined as nanopolymorphic HA.

To identify the possible measurable differences in surface morphology among the three surfaces, AFM quantitative assessments were performed. The results showed that roughness parameters such as root mean square roughness and peak-to-valley roughness were significantly increased for sandblasted surfaces and sandblasted + HA-coated surfaces compared to machined surfaces (Figure 3 ). There was no significant difference in these parameters between sandblasted surfaces and sandblasted + HA-coated surfaces, whereas three-dimensional AFM images $(5 \mu \mathrm{m} \times 5 \mu \mathrm{m})$ showed a clear distinction in that nanoscale roughness/topography was only recognizable on the HA-coated surface (top images in Figure 3). The interirregularity space was significantly greater for sandblasted surfaces than that for machined surfaces, while there was no such difference between machined surfaces and sandblasted + HA-coated surfaces. The most significant difference between sandblasted surfaces and sandblasted + HA-coated surfaces was in their surface area. Although the surface area of both sandblasted surfaces and sandblasted + HA-coated surfaces was significantly greater than that of machined surfaces, the surface area of sandblasted surfaces was $10 \%$ greater, whereas that of sandblasted + HA-coated surfaces was $76 \%$ greater than machined surfaces.

EDX chemical spectra illustrated that machined surfaces and sandblasted surfaces display all the elemental signals that constitute the Ti-6Al-4V alloy, ie, titanium, aluminum, and vanadium (Figure 4A). The machined implant contained little oxygen on its surface, while a clear peak of oxygen together with a heightened peak of aluminum appeared on the sandblasted
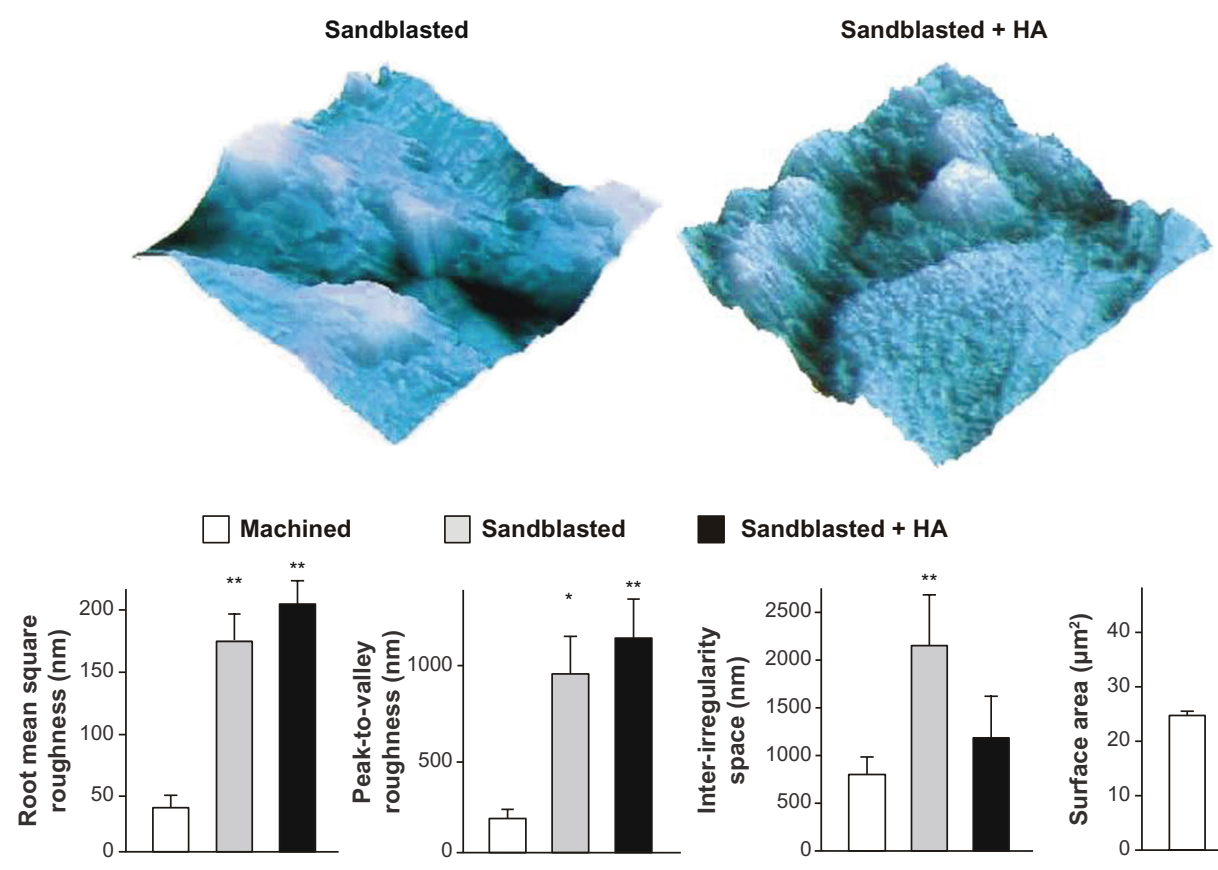

Sandblasted + HA

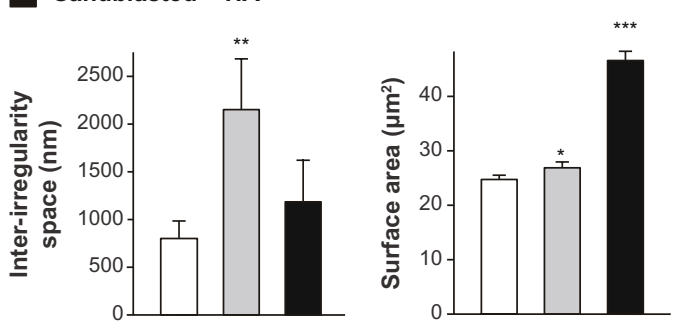

Figure 3 Quantitative measurement of surface roughness and surface area of the machined, sandblasted, and sandblasted + hydroxyapatite-coated surfaces using atomic force microscopy. Surface area was measured in a $5 \mu \mathrm{m} \times 5 \mu \mathrm{m}$ horizontal plane. Atomic force microscopic three-dimensional images $(5 \mu \mathrm{m} \times 5 \mu \mathrm{m})$ of sandblasted and sandblasted + hydroxyapatite-coated surfaces are also presented in a vertical scale of $800 \mathrm{~nm}$.

Notes: $* P<0.05$; $* * P<0.01$; $* * * P<0.001$, indicating a statistically significant difference compared to the machined surface $(\mathrm{n}=6)$.

Abbreviation: HA, hydroxyapatite. 
A

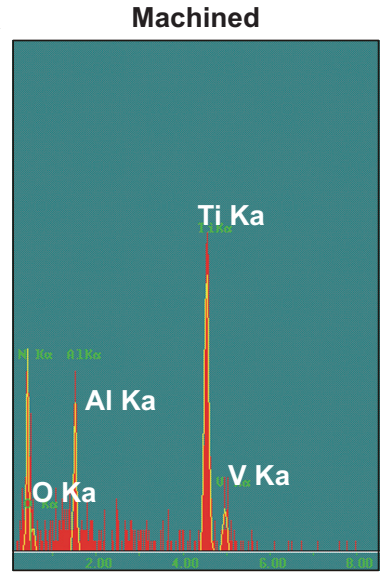

B

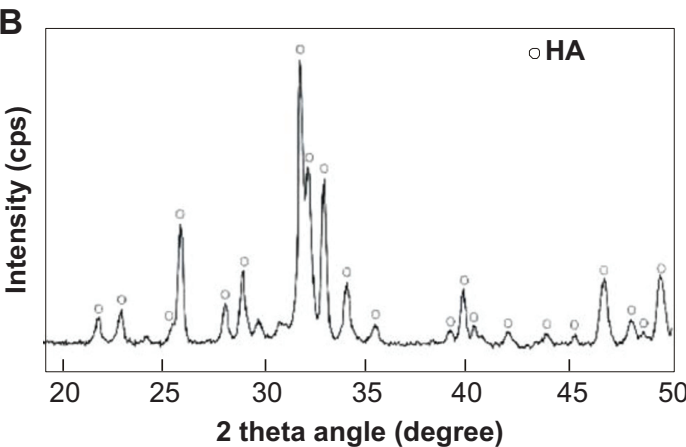

Sandblasted

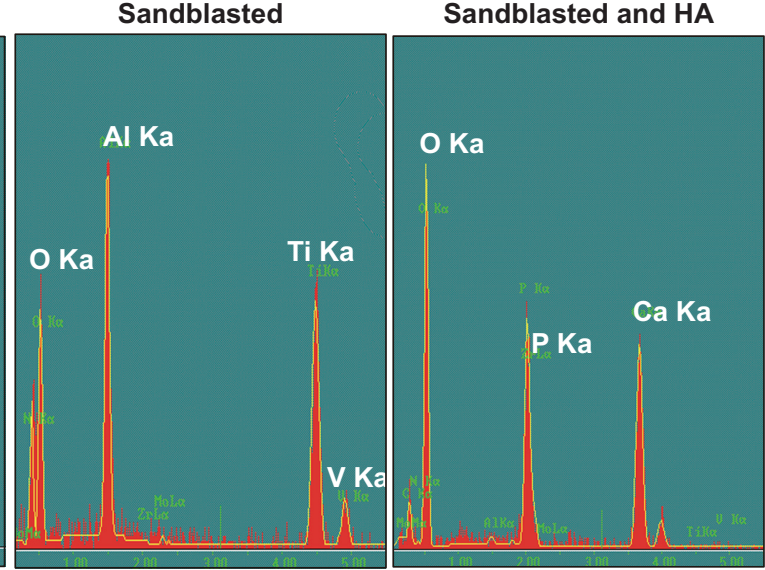

C

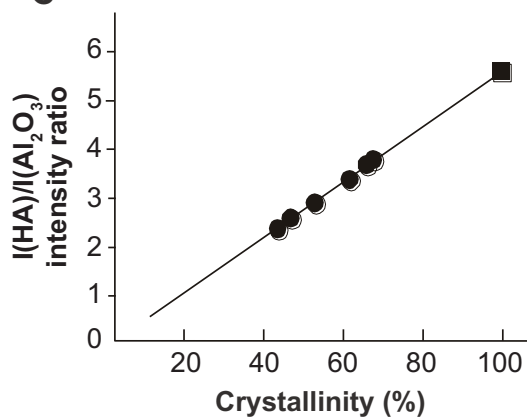

Figure 4 Surface chemistry and structural properties of sandblasted + hydroxyapatite-coated surfaces. (A) Surface chemistry spectra for machined, sandblasted, and sandblasted + hydroxyapatite-coated surfaces obtained from an energy dispersive X-ray spectroscopy. (B) A crystallographic pattern of sandblasted + hydroxyapatitecoated surfaces obtained by $X$-ray diffraction. The diffractogram shows the intensity peaks corresponding to those of hydroxyapatite. (C) Crystallinity assessment by $\mathrm{X}$-ray diffraction. The degree of crystallinity was determined by hydroxyapatite/aluminum oxide X-ray diffraction intensity ratio (black dots), where the hydroxyapatite/aluminum oxide ratio of the fully crystallized hydroxyapatite (hydroxyapatite sintered at $1000^{\circ} \mathrm{C}$ ) was used as $100 \%$ standard (black square).

Abbreviations: $\mathrm{Al}$, aluminum; $\mathrm{Al}_{2} \mathrm{O}_{3}$, aluminum oxide; $\mathrm{Ca}$, calcium; $\mathrm{HA}$, hydroxyapatite; $\mathrm{O}$, oxygen; $\mathrm{P}$, phosphorus; $\mathrm{Ti}$, titanium; $\mathrm{V}$, vanadium.

surfaces, presumably from the remnants of $\mathrm{Al}_{2} \mathrm{O}_{3}$ used for sandblasting. The spectrum for sandblasted + HA-coated surfaces showed strong peaks of $\mathrm{Ca}, \mathrm{P}$, and oxygen, where all elements of the titanium substrates, ie, titanium, aluminum, and vanadium, were completely masked, indicating a uniform and sufficiently thick HA coverage on the Ti-6Al-4V alloy.

Further chemical analyses were carried out using an inductively coupled plasma atomic emission spectrometer. The coated HA was scrutinized for potential impurities arising during the coating process. The results showed that no contaminants, ie, iron, nickel, chromium, copper, zinc, arsenic, and lead, were introduced during flame spray, with all contaminants having readings below the detection limit. The detection limit was $1 \mathrm{ppm}$ for iron, nickel, and copper and $5 \mathrm{ppm}$ for arsenic and lead. The $\mathrm{Ca} / \mathrm{P}$ molecular ratio obtained by the inductively coupled plasma atomic emission spectrometer was 1.66 , which is equivalent to the theoretical ratio of HA chemical formula. The XRD spectrum of coated HA exhibited low baseline intensities (low noise) and sharp peaks corresponding to those of ideal HA crystallites (Figure 4B). Together with the results showing no detectable impurities and the obtained $\mathrm{Ca} / \mathrm{P}$ ratio, this XRD result indicated that flame-sprayed molten HA was largely recrystallized to $\mathrm{HA}$ during calcination at $650^{\circ} \mathrm{C}$. The degree of crystallinity relative to that of fully crystallized HA was $55 \% \pm 9 \%$ (Figure 4C). These results conclusively demonstrated the successful formation of a virtually pure nanocrystalline HA on titanium by low-temperature flame spray and low-temperature calcination.

\section{Verification of the advantages of microroughened surfaces over nonmicroroughened surfaces}

As mentioned in the Introduction section, it was considered an important advancement in implant science and technology to ensure the potential and significant advantages of nanofeatured HA-coated titanium surfaces over commonly used microfeatured titanium surfaces. Therefore, a step-by-step procedure for comparing sandblasted microroughened titanium surfaces to machined nonmicrofeatured titanium 
surfaces was undertaken, followed by a comparison between sandblasted surfaces and nanopolymorphic HA-coated titanium surfaces.

The biomechanical strength of bone-implant integration, as evaluated by the push-in value, was higher for sandblasted surfaces than that for machined surfaces at healing time of weeks two and four (Figure 5). The difference was substantial, as high as $60 \%-80 \%$. However, at week eight, there was no difference in biomechanical strength. This is a result of the increasing push-in value for machined surfaces between weeks four and eight $(P<0.05)$, while the sandblasted surfaces had already reached a strength plateau. These results indicated that the sandblasted microroughened surface accelerated the establishment of biomechanical anchorage of implants but did not increase its final level compared to the machined, nonmicroroughened surface.

\section{Biomechanical strength of bone integration with nanopolymorphic crystalline HA}

After confirming the acceleration of bone-implant integration by sandblasted microroughened surfaces over machined nonmicroroughened surfaces, it was determined whether the level of bone-implant integration for nanopolymorphic HA-coated titanium surfaces would increase when compared to sandblasted surfaces. The addition of nanopolymorphic HA to microroughened surfaces resulted in a significant increase in the push-in value throughout the tested healing time from 2-8 weeks (Figure 6); the increase ranged from $50 \%$ to $70 \%$. Notably, the week two push-in value for

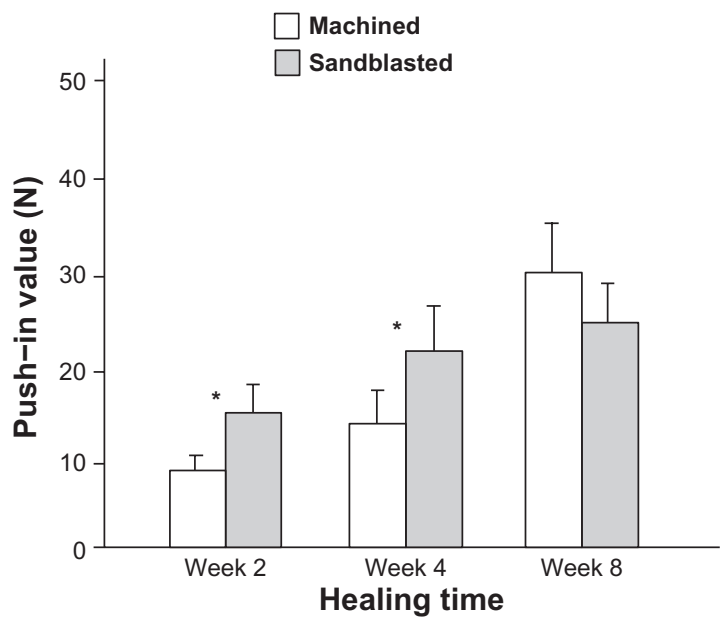

Figure 5 Microroughness-enhanced bone-titanium integration (implant anchorage in bone) evaluated by biomechanical push-in test. Push-in value of the machined and sandblasted implants at multiple healing times.

Notes: Data are shown as mean \pm standard deviation $(n=6) . * P<0.05$, indicating a statistically significant difference between the two surfaces.

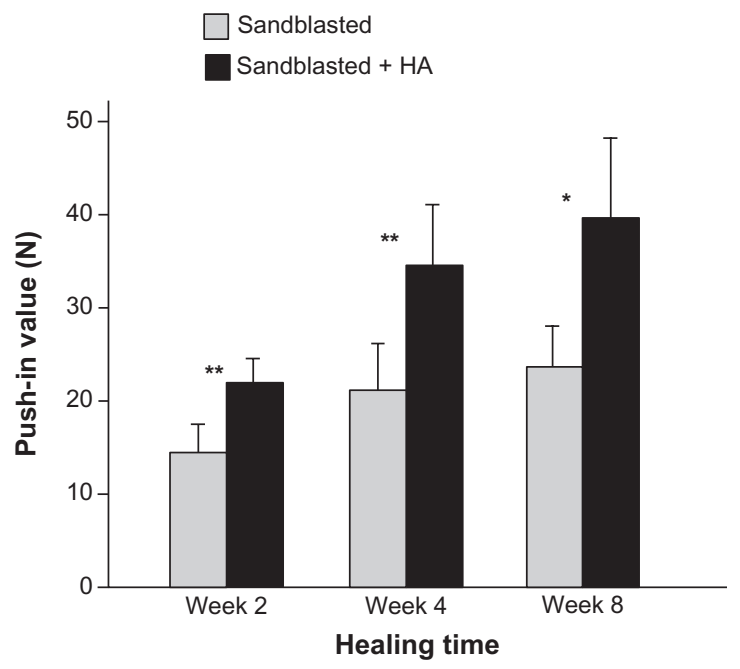

Figure 6 Nanopolymorphic crystalline hydroxyapatite-enhanced bone-titanium integration (implant anchorage in bone) evaluated by biomechanical push-in test. Push-in value of the sandblasted and sandblasted + hydroxyapatite-coated implants. Notes: Data are shown as mean \pm standard deviation $(n=6)$. $* P<0.05 ; * * p<0.01$, indicating a statistically significant difference between the two surfaces. Abbreviation: HA, hydroxyapatite.

sandblasted + HA-coated titanium surfaces was equivalent to the value for sandblasted surfaces at week eight. Moreover, the difference between the two surfaces remained constant even at the late healing stage of week eight.

\section{Bone-implant interfacial tissue properties of nanopolymorphic crystalline HA}

After the push-in test, the implant-tissue interface was examined by SEM and EDX for morphology and elemental composition, respectively. The typical SEM images of the implant-tissue complex of sandblasted surfaces and sandblasted + HA-coated surfaces taken at week two are presented in Figure 7A. In general, sandblasted surfaces showed remaining biological structures at the apical third of the implant surface (bone marrow area) (Figure 7C). The biological structures exhibited elemental peaks of $\mathrm{Ca}$ and $\mathrm{P}$ and were proven to be bone tissue (EDX spectrum in Figure 7C). However, the top two-thirds of the implants (cortical bone area) appeared similar in morphology to the original sandblasted surface with clear elemental peaks of aluminum and titanium but not of $\mathrm{Ca}$ or $\mathrm{P}$, indicating that the implant's bare surface was exposed (Figure 7B). This implied that either there was no new bone formation in this area or that the bone formed around the area was completely detached during the push-in test.

The apical two-thirds of sandblasted + HA-coated implants were extensively covered with a biological structure with $\mathrm{Ca}$ and $\mathrm{P}$ peaks (Figure 7A and $\mathrm{E}$ ). The biological 

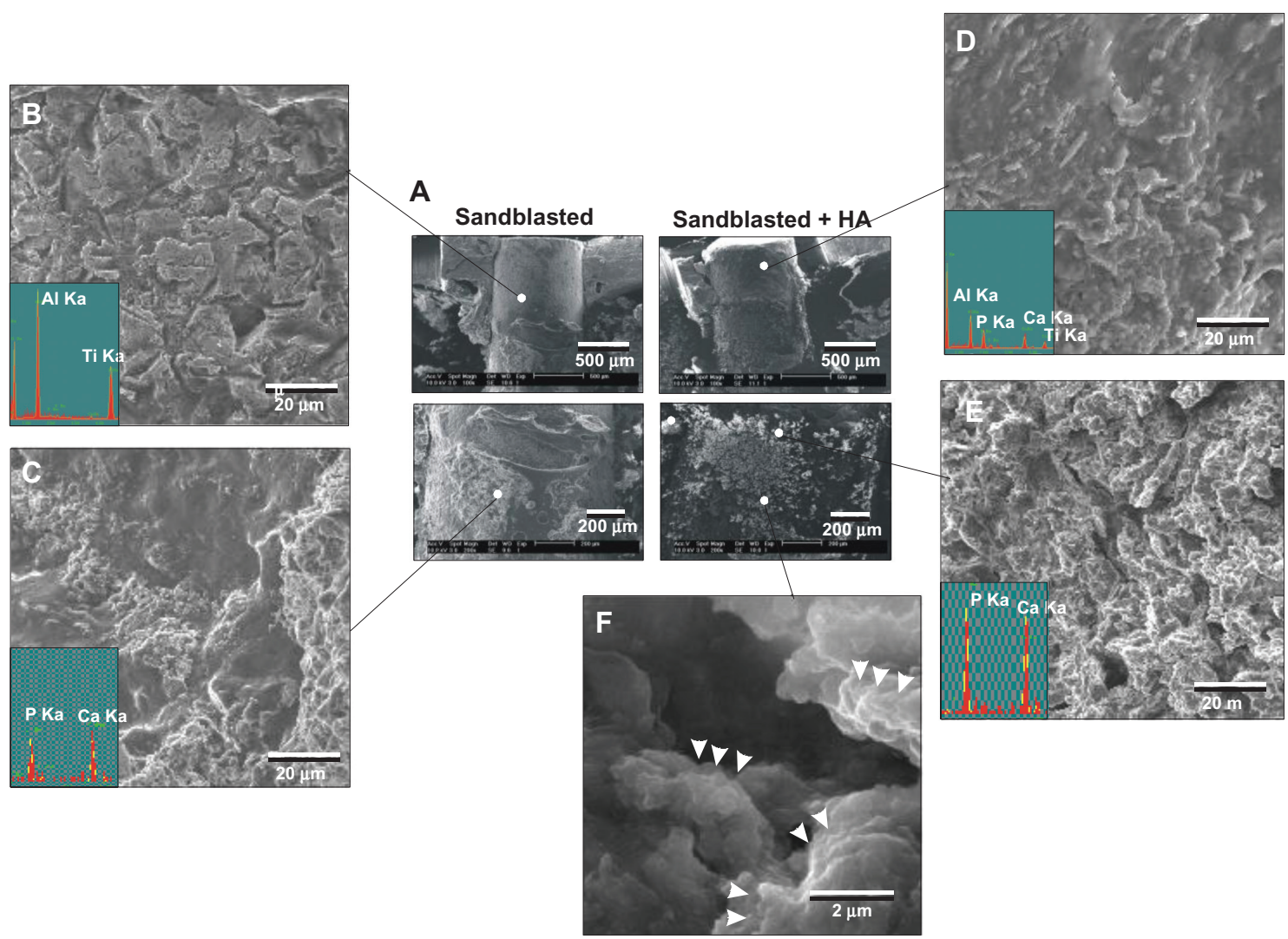

Figure 7 Morphological and elemental analyses of the sandblasted and sandblasted + hydroxyapatite-coated implant interfaces at early healing stage of week two. The implants were retrieved after push-in test and the tissue interfaces were exposed and analyzed by scanning electron microscopy and energy dispersive X-ray. (A) Representative low-magnification scanning electron microscopic images of the retrieved implants. (B and $\mathbf{C}$ ) High-magnification scanning electron microscopic images and energy dispersive X-ray spectra of the sandblasted surfaces for the areas indicated in (A). (D-F) High-magnification scanning electron microscopic images and energy dispersive X-ray spectrum of the sandblasted + hydroxyapatite-coated implant surfaces for the areas indicated in (A).

Abbreviations: Al, aluminum; $\mathrm{Ca}$, calcium; $\mathrm{HA}$, hydroxyapatite; $\mathrm{P}$, phosphorus; $\mathrm{Ti}$, titanium.

structures appeared morphologically different from the original surface of HA coating. Nanoscale globules (100-500 $\mathrm{nm}$ in diameter), suggestive of calcium-binding proteins such as osteopontin and osteocalcin, were found within the structure (arrowheads in Figure 7F). These findings indicated that these $\mathrm{Ca}$ - and P-positive biological structures were newly formed bone and not the coated layer of HA. The top third (cortical bone area) of the sandblasted + HA-coated surfaces was different in appearance to bone tissue or bare HA-coated surfaces, with detectable signals of aluminum and titanium in addition to $\mathrm{Ca}$ and $\mathrm{P}$ (Figure 7A and D). Since the aluminum and titanium signals were completely masked by HA coating on the original sandblasted + HA-coated surfaces, this indicated that the coated HA was partially detached, exposing the bare sandblasted surface during the push-in test.

After 4 weeks of healing, a large area of the sandblasted surface was not associated with biological tissue, having exposed the original implant surface (Figure 8A, B, and D). This area was free from $\mathrm{Ca}$ or $\mathrm{P}$ signals. This bone-free area appeared to be larger than the week two specimens. A small portion of the surface was covered with biological tissue that was positive for $\mathrm{Ca}$ and $\mathrm{P}$ signals (Figure 8C). In contrast, the apical two-thirds of the sandblasted + HA-coated surfaces were fully covered by biological tissues containing strong signals of $\mathrm{Ca}$ and $\mathrm{P}$ (Figure 8A and F). However, the top one-third showed similar morphology to the bare sandblasted roughened titanium surface with reduced $\mathrm{Ca}$ and $\mathrm{P}$ and emerged titanium and aluminum peaks (Figure 8E), indicating that the HA layer was partially detached during the push-in test.

\section{Bone morphogenesis around nanopolymorphic crystalline HA}

Histology sections obtained from week two specimens showed the concentric formation of new bone in a woven appearance around the sandblasted implants (Figure 9A). High-magnification images showed that bone formation around sandblasted surfaces was fragmentary and that an extensive portion of the bone tissue was separated from the 

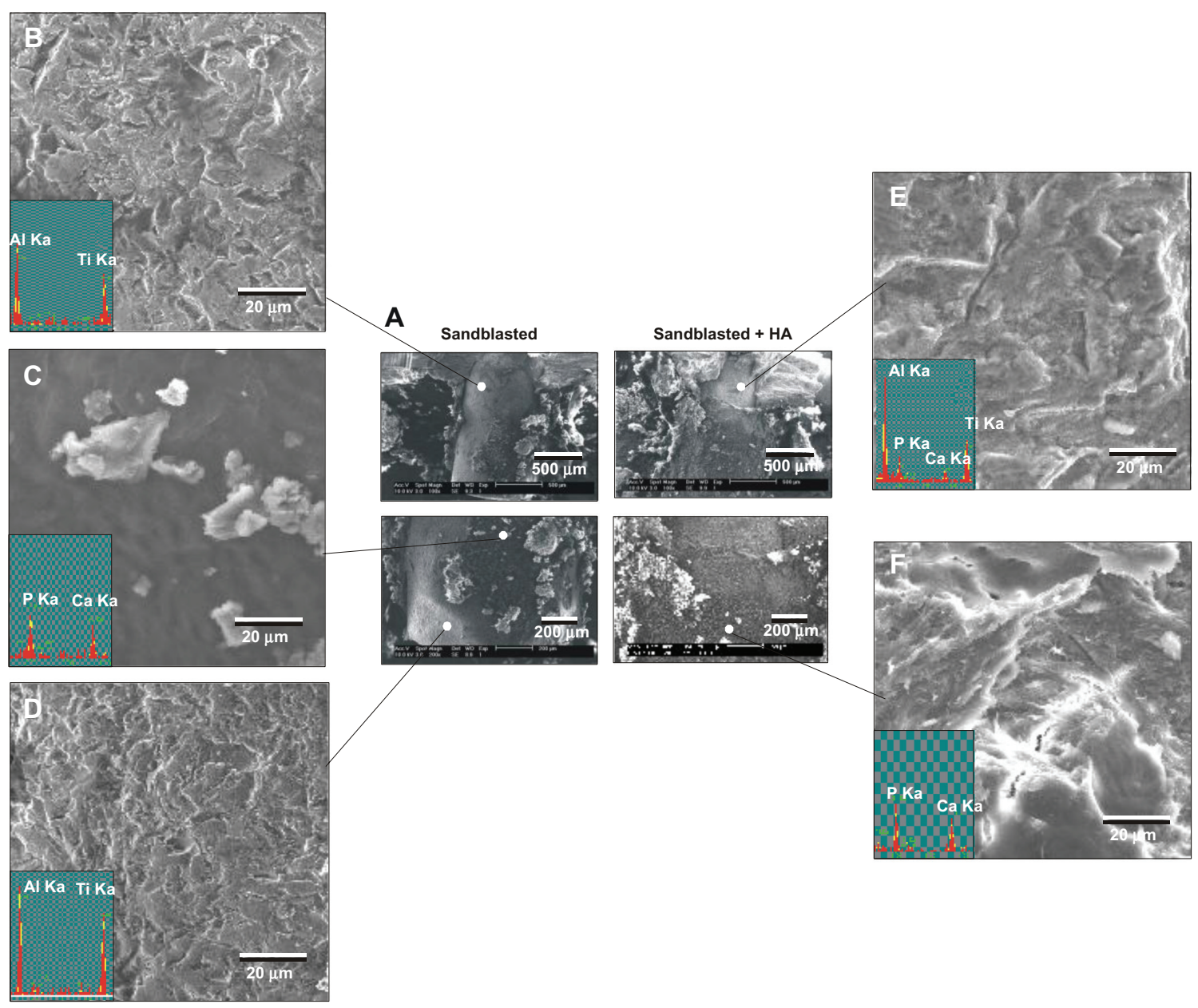

Figure 8 Morphological and elemental analyses of the sandblasted and sandblasted + hydroxyapatite-coated implant interfaces at late healing stage of week four by scanning electron microscopy and energy dispersive X-ray. (A) Representative low-magnification scanning electron microscopic images of the retrieved implants. (B-D) Highmagnification scanning electron microscopic images and energy dispersive $\mathbf{X}$-ray spectra of the sandblasted surfaces for the areas indicated in (A). (E and $\mathbf{F})$ High-magnification scanning electron microscopic images and energy dispersive $\mathbf{X}$-ray spectrum of the sandblasted + hydroxyapatite-coated implant surfaces for the areas indicated in (A).

Abbreviations: $\mathrm{Al}$, aluminum; Ca, calcium; HA, hydroxyapatite; $\mathrm{P}$, phosphorus; $\mathrm{Ti}$, titanium.

implant surface by soft tissue (white arrowheads). In contrast, a large area of the sandblasted + HA-coated surfaces was surrounded by a thin layer of new bone (black arrowheads). Around the sandblasted + HA-coated implants, there was a white circumferential zone of consistent thickness between the new bone and implant, which was assumed to be a layer of coated HA. Unlike the zone around the sandblasted surface, the newly formed bone around the sandblasted + HA-coated surfaces was rarely infiltrated by soft tissue. Bone formation around the sandblasted + HA-coated surfaces was extensive and contiguous.

At week four of healing, there was a larger area of bone formation around the sandblasted surfaces than was observed at week two (Figure 9B). Again, soft tissue infiltrated the implant interface in the large area of the bone around the sandblasted surfaces (white arrowheads), and only a small part of the bone was in direct contact with the implant surface.
New bone formation extended over almost the entire circumference of sandblasted HA-coated implants with minimum soft tissue infiltration. The bone was apparently thinner around the sandblasted + HA-coated surfaces than around the sandblasted surfaces.

Bone morphometry demonstrated that bone-implant contact was considerably higher for sandblasted + HA-coated surfaces than that for sandblasted surfaces at weeks two and four (Figure 9C). The difference was as much as four times greater at week two and 2.3 times at week four. Notably, the bone-implant contact reached $92 \%$ at week four around sandblasted + HA-coated surfaces and below $40 \%$ for sandblasted surfaces. Bone area in the near zone was significantly greater for sandblasted + HA-coated surfaces at week two but was comparable between the two surfaces at week four (Figure 9D). There was no difference in bone area in the far zone with and without HA 

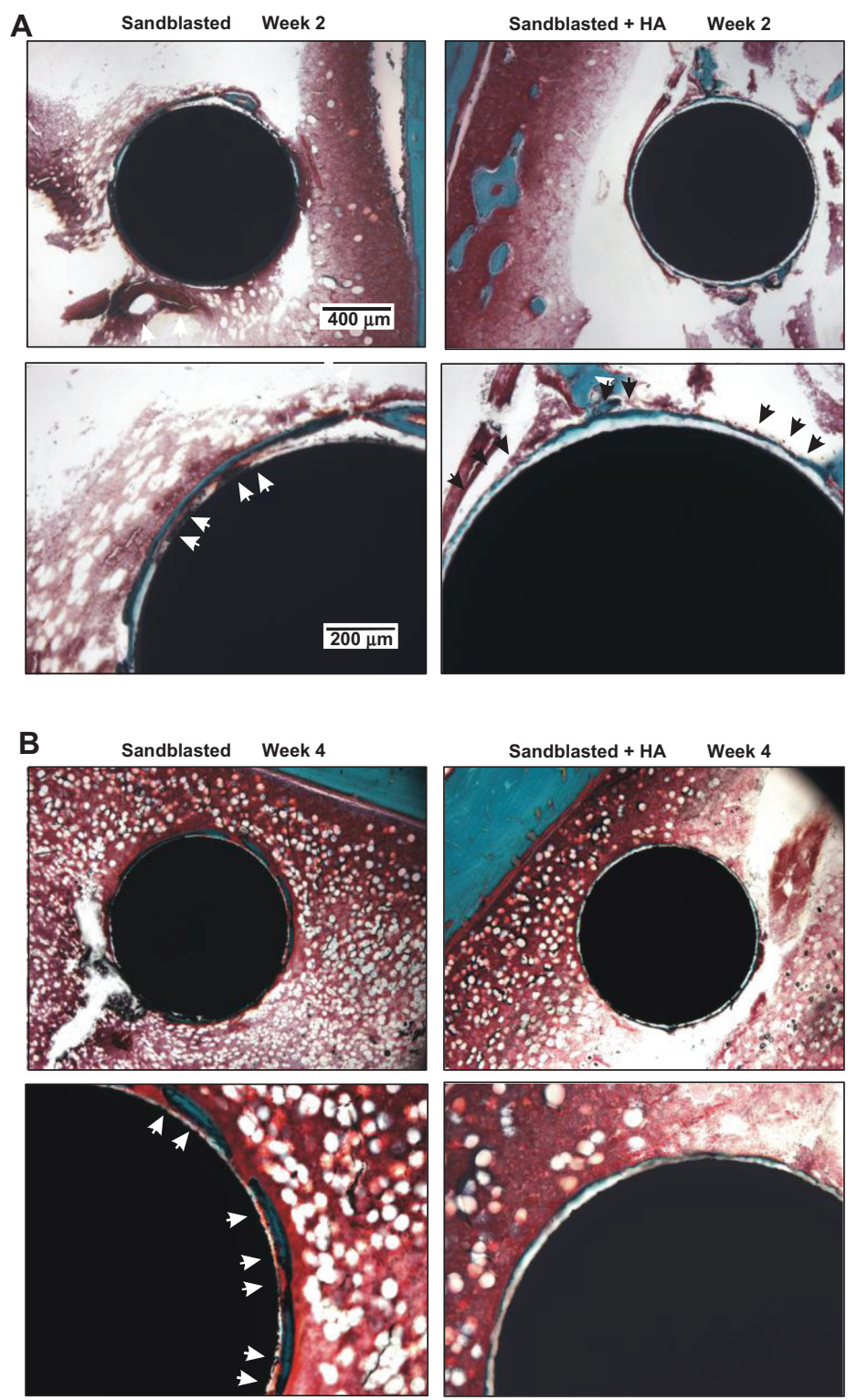
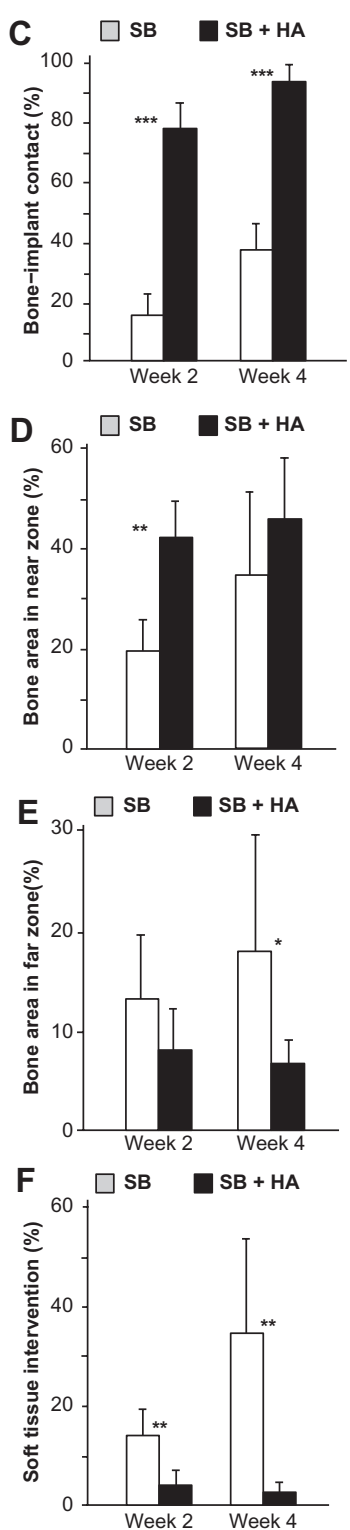

Figure 9 Nanopolymorphic crystalline hydroxyapatite-enhanced periimplant bone generation. (A and B) Representative histological images of the sandblasted and sandblasted + hydroxyapatite-coated implants with Goldner's trichrome stain at weeks two and four postimplantation. Average histomorphometric values of (C) boneimplant contact, (D) bone area in near zone, (E) bone area in far zone, and (F) soft tissue intervention are shown $(n=6)$.

Notes: $* P<0.05 ; * * P<0.01 ; * * * P<0.001$, indicating a statistically significant difference between the two surfaces.

Abbreviations: HA, hydroxyapatite; SB, sand blasted.

coating at week two. Interestingly, sandblasted surfaces showed 2.3 times greater bone area value at week four (Figure 9E). The percentage of soft tissue intervention was remarkably lower around the sandblasted + HA-coated surfaces (Figure 9F). The soft tissue intervention for the sandblasted + HA-coated surface was below $5 \%$ at week two and as low as $2 \%$ at week four in comparison to $34 \%$ for the sandblasted surfaces. Note that the percentage of soft tissue intervention increased from week two to week four around the sandblasted surfaces, while it decreased around the sandblasted + HA-coated surfaces.

\section{Discussion}

This study introduced a HA-coated titanium surface with complex nanomorphology consisting of nanoscale needlelike crystalline architectures developed in various diameters, lengths, and orientations. These nanofeatures were added to premicroroughened titanium surfaces, thereby creating an HA coat that can be considered a micro-nano-hybrid HA. More importantly, the addition of HA to the microroughened titanium surface has a demonstrated ability to increase the capability of bone-implant integration. This study was a meaningful advancement in nanotechnology and HA science 
particularly relevant to implant therapy, which confirmed the exclusive advantage of nanopolymorphic HA crystals over the microroughened surface.

The strength of implant anchorage is the most pertinent factor for evaluating the capability of implants to act as a load-bearing device. Adding the microfeature to the machined surface did not result in an increase in the push-in value at week eight, whereas the addition of nanopolymorphic crystalline HA increased the push-in value by $70 \%$ over the microroughened surface at this healing stage. Healing at week eight is considered the final stage of wound healing and implant integration in the rat model..$^{31}$ The clinical implication of these findings is that the nanopolymorphic crystalline HA-coated implants not only accelerated but also increased the level of bone-implant integration achieved. This validates the impact of this surface modification and suggests a compelling role for its use with load-bearing devices in dental and orthopedic therapeutics.

Bone-implant integration and implant osteoconductivity require a separate evaluation. For instance, morphological surface modification alone may increase the strength of implant anchorage without altering implant surface osteoconductivity by increasing surface area and roughness, leading to increased mechanical interlocking between the implant surface and bone. In this study, separate and comprehensive biomechanical and histological analyses were carried out to evaluate the strength of bone-implant integration and the potential modulation of osteoconductivity. Furthermore, in osteogenesis, the volume and speed of new bone formation are independent factors. To determine the mechanism that underlies better bone-implant integration around HA-coated titanium surfaces, it was crucial to isolate the individual parameters at specific time points during the healing process. To the authors' knowledge, no other systemic histological assessment has been performed on HA-coated titanium surfaces. Consequently, it is incompletely understood whether HA enhances the percentage of boneimplant contact or the volume of periimplant bone, or both.

To address the question, the following rationale was considered. Bone healing around implants can be described as a combination of new bone formation along implant surfaces, stimulated wound healing, and remodeling of the surrounding tissue. Furthermore, new bone formation in areas adjacent to and distant from the implant surface may involve different osteogenic processes, both of which are significant to the biomechanical potential of the load-bearing implant. In fact, the osseointegration process is regulated at the local level, and as such, can only be captured appropriately when the phenomenon is examined in the local environment, adjacent to the implant. ${ }^{34-36}$ If the analysis involves an excessive volume of surrounding tissues, the effect of the implant surface would be diluted, potentially resulting in a false negative result. To precisely and specifically identify the effect of titanium surface features on bone-implant integration, systematic bone histomorphometry is required. ${ }^{34}$

Therefore, this study examined the morphology of osteogenesis at multiple time points in two different zones surrounding the implant surface. The distinct results obtained from the examination of the different zones retrospectively justified this approach. The increased anchorage surrounding the nanopolymorphic crystalline HA-coated implants was not simply explained by the increased volume of bone formation around the surface. A consistent increase in the percentage of bone-implant contact was found at two different time points, with four times as much contact at week two and 2.3 times at week four. The bone-implant contact around HA-coated surfaces at week four was as high as $90 \%$ which is remarkable compared to $45 \% \pm 16 \%{ }^{37}$ or $50 \%-65 \%,{ }^{34}$ which is generally reported for modern titanium implant surfaces in the literature. However, the amount of bone formation was not uniformly increased by the HA coat, with the increase only found in the bone area in the near zone only at the early healing stage of week two. The bone area in the far zone was not affected by the presence of HA nanopolymorphic crystals at week two and was reduced at week four. This coincided with a thin microscopically-observed osteogenesis. Thus, the effect of nanopolymorphic crystalline HA on periimplant osteogenesis clearly differed inside and outside the $50 \mu \mathrm{m}$ boundary of the local environment. In this study, histology was not performed at week eight of healing. The push-in values for the sandblasted surfaces and sandblasted + HA-coated surfaces did not significantly increase between weeks four and eight as shown in the results, while maintaining significant difference between the two surfaces. These indicate that periimplant bone generation reached a stable stage of osseointegration and bone remodeling during this time period. Therefore, it was speculated that there would be significant differences in histomorphometric parameters at week eight. As mentioned above, the boneimplant contact is $50 \%-65 \%$ at best in the literature and $90 \%$ bone-implant contact obtained by sandblasted + HA-coated surfaces is unlikely to be excelled by the sandblasted surfaces even after longer healing time. These need to be confirmed in future histological studies covering longer healing time.

In addition to the increased bone-implant contact, there was also a notable decrease in the percentage of soft tissue intervention surrounding implants with nanopolymorphic crystalline HA. For instance, soft tissue intervention at week two was reduced from $14.5 \%$ to $3.5 \%$ by HA coating the 
microroughened surfaces. While the microroughened surface increased the soft tissue intervention to more than $30 \%$ during the progressive healing from week two to week four, HA coating suppressed it to as low as $2.1 \%$. Thus, this study identified in vivo biological parameters, sensitively responding to the bone-implant integration, which were altered by nanofeatured HA beyond the one altered by microroughening of titanium surfaces. These parameters will help to critically assess new implant surfaces in the future and to track specific biological advancements brought by these new surfaces.

The results of bone histomorphometry and implant-tissue interfacial analyses were in agreement. The extensive area of sandblasted surface was not associated with bone after the push-in test, implying that either there was no bone formation in this area or that newly formed bone had detached during the push-in test. The high percentage of soft tissue infiltration found by histomorphometry explained this observation. Even if there was bone formation, the limited adhesive strength between the implant and bone may have resulted in the detachment of the bone. In addition, the poor quality bone tissue remnant present at week four on the sandblasted surfaces was explained by the increasing percentage of soft tissue infiltration between weeks two and four around the surfaces. In contrast, an extensive area of HA-coated surfaces had bone tissue remaining after the push-in test, supporting the bone morphometric results that showed greater bone-implant contact and near zone bone volume. In addition, the bonding strength between HA and bone can be assumed to be stronger than that between sandblasted surfaces and bone because of the very low percentage of soft tissue intervention. Even for HA-coated surfaces, the cortical part of the implant surface was rarely accompanied with bone after the push-in test. The reduced $\mathrm{Ca}$ and $\mathrm{P}$ peaks around the HA-coated surfaces in this area suggested that the coated HA was at least partially lost during the push-in test. Bone bonding to HA may be stronger than the bonding between HA and the titanium substrate. The HA in the present study was partially crystallized and may have different mechanical properties from those reported in the literature. In addition, HA detachment potentially happening due to chemical solubility cannot be ruled out.

As separate aspects of osteogenesis, the volume and speed of new bone formation are regulated independently: the bone mass is determined by the quantity of osteogenic cells, while the speed of bone formation is determined by the rate of differentiation. There is an inverse correlation between the rates of proliferation and differentiation in osteoblasts. ${ }^{38-40}$ For instance, biomaterial surfaces with rougher textures generally promote osteoblast differentiation ${ }^{31,34,41,42}$ However, they also reduce osteoblast proliferation. ${ }^{41,43-45}$ Accordingly, the bone mass around the roughened surfaces is smaller than that around relatively smooth surfaces ${ }^{36}$ In the present study, bone formation around HA-coated surfaces was described as having osteogenesis that was rapid and localized in close proximity to the coated surface. The rapid bone formation implies that osteogenic cells may have differentiated faster on the surface, as reported in the literature on cell-HA interaction. ${ }^{23,46,22}$ In addition, increased cell recruitment and attachment to HA-coated surfaces may enable rapid bone formation. ${ }^{19,20}$ However, because of this promoted differentiation, the rate of proliferation may have been reduced, resulting in the formation of thin bone tissue and the reduced mass of periimplant bone. When HA in low crystallinity is solubilized, it may elevate the local $\mathrm{pH}$ and decrease cell proliferation, ${ }^{19}$ which also may explain the smaller bone volume around the HA.

To create nanofeatures on the coated HA, calcination was used, with thermal treatment at a relatively low temperature of $650^{\circ} \mathrm{C}$, instead of sintering at higher temperatures. In general, HA crystallizes almost completely by heating at temperature of $1000^{\circ} \mathrm{C}$ or higher. Most of the commercially available and experimentally prepared HA-coated implants in the literature are sintered and show few microfeatures and no nanofeatures, although they often show supra-microscale roughness or irregularity. ${ }^{18,46,22}$ In this study, HA nanocrystallites with 55\% crystallinity and a $\mathrm{Ca} / \mathrm{P}$ ratio of 1.66 were successfully created. The $55 \%$ crystallinity was within the range of the commercially available HA-coated implants, which varies from $44 \%$ to $96 \% .{ }^{17,18}$ Low levels of crystallization in HA may be preferred to promote cellular osteogenic activities. ${ }^{19}$ The compositional accuracy achieved by the spray technique used in this study may also have affected the successful nanocrystallites formation. To maintain the $\mathrm{Ca} / \mathrm{P}$ ratio and avoid potential impurities during the spraying procedure, a low-temperature flame spray was used - its purity was verified by chemical analyses. Pure $\mathrm{HA}, \mathrm{Ca}_{10}\left(\mathrm{PO}_{4}\right)_{6}(\mathrm{OH})_{2}$, forms hexagonal crystal structures with a stoichiometric $\mathrm{Ca} / \mathrm{P}$ ratio of $1.67 .{ }^{47} \mathrm{The} \mathrm{Ca} / \mathrm{P}$ ratio of the HA obtained by low-temperature flame spray was close to this stoichiometric ratio. The present XRD results demonstrated that the low-temperature flame-spray HA had well-defined spectrum peaks, similar to those observed for stoichiometric HA crystals. $^{18}$

In biomaterials research, the surface chemistry and morphology of materials are interdependent. Consequently, it is extremely difficult to isolate the effect of surface chemistry from morphology. ${ }^{48}$ For instance, when titanium samples with different surface morphologies were compared in the literature, these samples invariably involved different 
surface chemistry. ${ }^{33,49}$ As shown in the results of various surface characterizations, coated HA involves a drastic alteration in surface morphology, with a simultaneous change in surface chemistry when compared to sandblasted microroughened titanium surfaces. As a result, the increased bone-integration capability of HA-coated surfaces may not be due to the added surface chemistry of HA but rather a result of the modified surface topography. AFM analysis demonstrated that despite limited alteration of surface roughness with and without HA coating, the interirregularity space was significantly reduced and the surface area was significantly increased on HA-coated surfaces. In addition, the new nanofeatures that arise in HA coating should not be ignored, although these were below the resolution limit of AFM and could not be quantitatively detected. Future studies will address the interaction of surface chemistry and morphology on the HA-coated surfaces and determine if the effects are additive, counteracting, independent, or synergistic. The authors believe there must have been collaborative effects of surface chemistry and morphology in some instances; for instance, the increased surface area of HA may make phosphate release more efficient, which increases the efficiency of calcium deposition during matrix mineralization. Despite the biological mechanism that needs to be addressed in the future, this study demonstrated that a combination of flame spray and low-temperature calcination enables the formation of nanopolymorphic HA with favorable crystallographic and chemical properties on microroughened titanium. Furthermore, the study showed that these HA-coated implants resulted in a considerable enhancement of boneimplant integration and periimplant osteogenesis.

\section{Conclusion}

This study introduced a successful formation of nanopolymorphic crystalline HA on microroughened titanium surfaces using a combination of flame spray and low-temperature calcination. The coated HA consisted of nanoscale needle-like architectures in various diameters, lengths, and orientations. This HA was proven to have crystallographic and chemical properties favorable to in vivo osteogenesis. HA-coating on titanium implants increased the strength of bone-implant integration compared to noncoated microroughened titanium implants consistently at early and late stages of healing. This was supported by the increased percentage of bone-implant contact and bone volume within a $50 \mu \mathrm{m}$ border of the implant surface and a remarkably reduced percentage of soft tissue intervention between bone and the implant surface. However, bone volume outside the $50 \mu \mathrm{m}$ border was reduced around HA-coated implants. Thus, this study demonstrated that the addition of nanopolymorphic crystalline HA to microroughened titanium not only accelerates but also increases the level of bone-implant integration and identified specific bone morphogenesis parameters that are improved by the HA coat.

\section{Acknowledgments}

This study has, in part, been supported by Japan Medical Materials Corporation. This study was conducted in a facility constructed with support from the Research Facilities Improvement Program (Grant No C06RR014529) of the National Center for Research Resources, National Institute of Health.

\section{Disclosure}

The authors report no conflicts of interest in this work.

\section{References}

1. Mendonca G, Mendonca DB, Aragao FJ, Cooper LF. Advancing dental implant surface technology - from micron- to nanotopography. Biomaterials. 2008;29(28):3822-3835.

2. Svanborg LM, Andersson M, Wennerberg A. Surface characterization of commercial oral implants on the nanometer level. J Biomed Mater Res B Appl Biomater. 2010;92(2):462-469.

3. Wennerberg A, Albrektsson T. On implant surfaces: a review of current knowledge and opinions. Int J Oral Maxillofac Implants. 2010;25(1):63-74.

4. Guo J, Padilla RJ, Ambrose W, De Kok IJ, Cooper LF. The effect of hydrofluoric acid treatment of $\mathrm{TiO} 2$ grit blasted titanium implants on adherent osteoblast gene expression in vitro and in vivo. Biomaterials. 2007;28(36):5418-5425.

5. Khang D, Lu J, Yao C, Haberstroh KM, Webster TJ. The role of nanometer and sub-micron surface features on vascular and bone cell adhesion on titanium. Biomaterials. 2008;29(8):970-983.

6. Kubo K, Tsukimura N, Iwasa F, et al. Cellular behavior on $\mathrm{TiO} 2$ nanonodular structures in a micro-to-nanoscale hierarchy model. Biomaterials. 2009;30(29):5319-5329.

7. Tsukimura N, Yamada M, Iwasa F, et al. Synergistic effects of UV photofunctionalization and micro-nano hybrid topography on the biological properties of titanium. Biomaterials. 2011;32(19):4358-4368.

8. Variola F, Yi JH, Richert L, Wuest JD, Rosei F, Nanci A. Tailoring the surface properties of Ti6Al4V by controlled chemical oxidation. Biomaterials. 2008;29(10):1285-1298.

9. Hori N, Iwasa F, Ueno T, et al. Selective cell affinity of biomimetic micro-nano-hybrid structured $\mathrm{TiO} 2$ overcomes the biological dilemma of osteoblasts. Dent Mater. 2010;26(4):275-287.

10. Biggs MJ, Richards RG, Dalby MJ. Nanotopographical modification: a regulator of cellular function through focal adhesions. Nanomedicine. 2010;6(5):619-633.

11. Wennerberg A, Albrektsson T. Effects of titanium surface topography on bone integration: a systematic review. Clin Oral Implants Res. 2009;20 Suppl 4:172-184.

12. Khang D, Carpenter J, Chun YW, Pareta R, Webster TJ. Nanotechnology for regenerative medicine. Biomed Microdevices. 2010;12(4):575-587.

13. Sanchez C, Arribart H, Guille MM. Biomimetism and bioinspiration as tools for the design of innovative materials and systems. Nat Mater. 2005;4(4):277-288.

14. Ogawa T, Saruwatari L, Takeuchi K, Aita H, Ohno N. Ti nanonodular structuring for bone integration and regeneration. $J$ Dent Res. 2008;87(8):751-756.

15. Dalby MJ, Gadegaard N, Curtis AS, Oreffo RO. Nanotopographical control of human osteoprogenitor differentiation. Curr Stem Cell Res Ther. 2007;2(2):129-138. 
16. Dalby MJ, McCloy D, Robertson M, et al. Osteoprogenitor response to semi-ordered and random nanotopographies. Biomaterials. 2006;27(15):2980-2987.

17. Yang Y, Kim KH, Ong JL. A review on calcium phosphate coatings produced using a sputtering process - an alternative to plasma spraying. Biomaterials. 2005;26(3):327-337.

18. Burgess AV, Story BJ, La D, Wagner WR, LeGeros JP. Highly crystalline MP-1 hydroxylapatite coating. Part I: in vitro characterization and comparison to other plasma-sprayed hydroxylapatite coatings. Clin Oral Implants Res. 1999;10(4):245-256.

19. Chou L, Marek B, Wagner WR. Effects of hydroxylapatite coating crystallinity on biosolubility, cell attachment efficiency and proliferation in vitro. Biomaterials. 1999;20(10):977-985.

20. Kilpadi KL, Chang PL, Bellis SL. Hydroxylapatite binds more serum proteins, purified integrins, and osteoblast precursor cells than titanium or steel. J Biomed Mater Res. 2001;57(2):258-267.

21. Ong JL, Chan DC. Hydroxyapatite and their use as coatings in dental implants: a review. Crit Rev Biomed Eng. 2000;28(5-6):667-707.

22. Perizzolo D, Lacefield WR, Brunette DM. Interaction between topography and coating in the formation of bone nodules in culture for hydroxyapatite- and titanium-coated micromachined surfaces. J Biomed Mater Res. 2001;56(4):494-503.

23. Ozawa S, Kasugai S. Evaluation of implant materials (hydroxyapatite, glass-ceramics, titanium) in rat bone marrow stromal cell culture. Biomaterials. 1996;17(1):23-29.

24. Burgess AV, Story BJ, Wagner WR, Trisi P, Pikos MA, Guttenberg SA. Highly crystalline MP-1 hydroxylapatite coating. Part II: in vivo performance on endosseous root implants in dogs. Clin Oral Implants Res. 1999;10(4):257-266.

25. Story BJ, Burgess AV, La D, Wagner WR. In vitro stability of a highly crystalline hydroxylapatite coating in a saturated citric acid solution. J Biomed Mater Res. 1999;48(6):841-847.

26. Chou YF, Chiou WA, Xu Y, Dunn JC, Wu BM. The effect of pH on the structural evolution of accelerated biomimetic apatite. Biomaterials. 2004;25(22):5323-5331.

27. Chou YF, Huang W, Dunn JC, Miller TA, Wu BM. The effect of biomimetic apatite structure on osteoblast viability, proliferation, and gene expression. Biomaterials. 2005;26(3):285-295.

28. Oyane A, Kawashita M, Nakanishi K, et al. Bonelike apatite formation on ethylene-vinyl alcohol copolymer modified with silane coupling agent and calcium silicate solutions. Biomaterials. 2003;24(10):1729-1735.

29. Kawashita M, Nakao M, Minoda M, et al. Apatite-forming ability of carboxyl group-containing polymer gels in a simulated body fluid. Biomaterials. 2003;24(14):2477-2484.

30. Tanahashi M, Yao T, Kokubo T, et al. Apatite coated on organic polymers by biomimetic process: improvement in its adhesion to substrate by glow-discharge treatment. J Biomed Mater Res. 1995;29(3): 349-357.

31. Ogawa T, Ozawa S, Shih JH, et al. Biomechanical evaluation of osseous implants having different surface topographies in rats. $J$ Dent Res. 2000;79(11):1857-1863.

32. Ueno T, Yamada M, Suzuki T, et al. Enhancement of bone-titanium integration profile with UV-photofunctionalized titanium in a gap healing model. Biomaterials. 2010;31(7):1546-1557.
33. Aita H, Hori N, Takeuchi M, et al. The effect of ultraviolet functionalization of titanium on integration with bone. Biomaterials. 2009;30(6): $1015-1025$.

34. Ogawa T, Nishimura I. Different bone integration profiles of turned and acid-etched implants associated with modulated expression of extracellular matrix genes. Int J Oral Maxillofac Implants. 2003;18(2): 200-210.

35. Ogawa T, Nishimura I. Genes differentially expressed in titanium implant healing. J Dent Res. 2006;85(6):566-570.

36. Ogawa T, Sukotjo C, Nishimura I. Modulated bone matrix-related gene expression is associated with differences in interfacial strength of different implant surface roughness. J Prosthodont. 2002;11(4):241-247.

37. Weinlaender M, Kenney EB, Lekovic V, Beumer J 3rd, Moy PK, Lewis S. Histomorphometry of bone apposition around three types of endosseous dental implants. Int J Oral Maxillofac Implants. 1992;7(4):491-496.

38. Stein GS, Lian JB. Molecular mechanisms mediating proliferation/ differentiation interrelationships during progressive development of the osteoblast phenotype. Endocr Rev. 1993;14(4):424-442.

39. Siddhanti SR, Quarles LD. Molecular to pharmacologic control of osteoblast proliferation and differentiation. J Cell Biochem. 1994;55(3):310-320.

40. Alborzi A, Mac K, Glackin CA, Murray SS, Zernik JH. Endochondral and intramembranous fetal bone development: osteoblastic cell proliferation, and expression of alkaline phosphatase, m-twist, and histone $\mathrm{H} 4$. J Craniofac Genet Dev Biol. 1996;16(2):94-106.

41. Takeuchi K, Saruwatari L, Nakamura HK, Yang JM, Ogawa T. Enhanced intrinsic biomechanical properties of osteoblastic mineralized tissue on roughened titanium surface. J Biomed Mater Res A. 2005;72(3):296-305.

42. Cooper LF, Masuda T, Yliheikkila PK, Felton DA. Generalizations regarding the process and phenomenon of osseointegration. Part II In vitro studies. Int J Oral Maxillofac Implants. 1998;13(2):163-174.

43. Bachle M, Kohal RJ. A systematic review of the influence of different titanium surfaces on proliferation, differentiation and protein synthesis of osteoblast-like MG63 cells. Clin Oral Implants Res. 2004;15(6):683-692.

44. Zhao G, Schwartz Z, Wieland M, et al. High surface energy enhances cell response to titanium substrate microstructure. J Biomed Mater Res A. 2005;74(1):49-58.

45. Boyan BD, Bonewald LF, Paschalis EP, et al. Osteoblast-mediated mineral deposition in culture is dependent on surface microtopography. Calcif Tissue Int. 2002;71(6):519-529.

46. Ong JL, Hoppe CA, Cardenas HL, et al. Osteoblast precursor cell activity on HA surfaces of different treatments. J Biomed Mater Res. 1998;39(2):176-183.

47. Kay MI, Young RA, Posner AS. Crystal structure of hydroxyapatite. Nature. 1964;204:1050-1052.

48. Saruwatari L, Aita H, Butz F, et al. Osteoblasts generate harder, stiffer, and more delamination-resistant mineralized tissue on titanium than on polystyrene, associated with distinct tissue micro- and ultrastructure. J Bone Miner Res. 2005;20(11):2002-2016.

49. Tsukimura N, Kojima N, Kubo K, et al. The effect of superficial chemistry of titanium on osteoblastic function. J Biomed Mater Res A 2008;84(1):108-116.
International Journal of Nanomedicine

\section{Publish your work in this journal}

The International Journal of Nanomedicine is an international, peerreviewed journal focusing on the application of nanotechnology in diagnostics, therapeutics, and drug delivery systems throughout the biomedical field. This journal is indexed on PubMed Central,

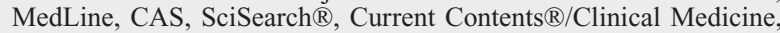

\section{Dovepress}

Journal Citation Reports/Science Edition, EMBase, Scopus and the Elsevier Bibliographic databases. The manuscript management system is completely online and includes a very quick and fair peer-review system, which is all easy to use. Visit http://www.dovepress.com/ testimonials.php to read real quotes from published authors 